\title{
Editorials
}

\section{Early Psychosis: Where we've been, where we still have to go}

\author{
EÓIN KILLACKEY, ALISON R. YUNG, PATRICK D. MC GORRY
}

\begin{abstract}
Early intervention in psychosis, while not a new concept, has seen great development over the last 15 years. Growth in this time has occurred in a number of areas and has attracted a broad coalition of researchers, consumers, clinicians, carers and policy makers. In this time the concept of early intervention has moved from the fringes to the mainstream of clinical approaches to psychosis in many places, and is doing so in even more. After a decade and a half, this paper reviews some of the key issues that have been addressed and points to areas where further growth and reform is still required. Some issues that have created controversy are examined here including pre-onset intervention and identification, the relationship of duration of untreated psychosis (DUP) to outcome and whether or not early intervention is an effective and economically viable model. Areas that are only now developing or which require further investigation are considered, including the concept of stages of mental illness and concomitant interventions, closing the efficacy-effectiveness gap and an increased focus on functioning as part of the recovery process. Early intervention in psychosis started as a reformist movement, agitating for change from outside the mainstream. Change has occurred and now early intervention is part of the mainstream approach to psychotic illness. In order to continue to develop, while enjoying the benefits of being a mainstream intervention, early intervention must not stray too far from its reformist roots.
\end{abstract}

\section{INTRODUCTION}

The idea that the early phase of psychotic illness is an opportune target of intervention has a long history in psychiatry (Sullivan, 1927). Despite this, for most of the twentieth century little was done to move the focus of care from long term management of chronic illness, to preventative and rehabilitative early intervention. It was not until 1992 that the field of early psychosis research and practice really began to develop (Killackey \& Yung, 2007; Verdoux \& Cougnard, 2003). Since that time there has been an exponential growth in research, leading to large changes to clinical service delivery in several places. A community of researchers, clinicians, consumers, carers and policy makers has formed to drive forward the early intervention agenda. This has been done through building networks, meetings, advocacy and education. The concept of early intervention in psychosis is no longer a fringe idea and has been adopted and recommended in several international treatment guidelines (McGorry et al., 2005; NICE, 2003).

There are many questions which have been studied for the whole or most of the last 15 years. These include: whether or not psychosis is preventable; if delay in treatment has deleterious consequences in outcome and; if so, can this delay be effectively reduced. At the same time new concepts and questions are emerging. These include: the idea of the staging model (McGorry et al., 2006) of illness which seeks to capture the development of mental illness so as to identify the most benign interventions at the earliest point; understanding recovery to be more than just symptomatic improvement or the prevention of symptomatic exacerbation or onset, but to also include a return to functional living (Killackey et al,, 2006); the development of new pharmacological and psychosocial approaches to treatment and the implementation of these treatments in routine practice in order to close the efficacy-effectiveness gap (McGorry, 2005).

After 15 years it is an apt time to review the state of the field, identifying progress in resolving the questions which have dominated debate in the early psychosis field, and more importantly to identify and describe areas in which clinical practice and research needs to continue to develop if the spirit of reform which has charged the development of early intervention is not to stall.

\section{PRE-ONSET IDENTIFICATION AND PREVENTION OF ILLNESS}

One of the most provocative questions posed by the pioneers of research into early psychosis was 'Is it possi-

\footnotetext{
Address for correspondence: Dr. E. Killackey, ORYGEN Research Centre, 35 Poplar Road, Parkville, Victoria 3052 (Australia).

E-mail: eoin@unimelb.edu.au

Declaration of Interest: None.
} 
ble to prevent psychotic illness?' This involved two separate investigations (Francey et al., 2005; Yung et al., 2004). Firstly, is it possible to identify people at risk of experiencing a mental illness before the onset of that illness? Secondly, having identified them is there a way of preventing, delaying or ameliorating the onset of their illness?

Are we able to identify people at risk of psychosis?

Identification of people at risk for developing psychosis, while difficult (Hambrecht et al., 2002), is the key element of pre-onset intervention. Because psychotic illnesses have low base rates, large scale screening of the general population is not likely to be viable (McGorry \& Killackey, 2002). In response, several strategies have been developed in order to identify high-risk groups. Based on the idea of indicated prevention (Mrazek \& Haggerty, 1994), and reducing false positive rates using 'multiple-gate screening' and 'close in' follow-up of cohorts selected as being at risk of developing a psychosis (Bell, 1992), 'At Risk Mental State' (ARMS) or Ultra High Risk (UHR) criteria were developed, initially at the PACE clinic in Melbourne, Australia and since adapted for use in many places (Mason et al., 2004; Yung et al., 2004). Basic symptom criteria have been used in a similar way in German-speaking countries. Using these criteria studies have found transition rates between $9.4 \%$ and $70 \%$ with a mean of $31 \%$ (Yung et al., 2004).

Despite these gains, there have been criticisms made of the methods used to increase the level of prediction from the general population rate of $1 \%$ to a base rate of $30 \%$ (Warner, 2001; 2002; 2005). One of the criticisms is that the screening process would not be effective in the general population because of the lower base rate of psychotic illness in that population (Warner, 2005). While this is true, pre-onset identification is predicated on indicated, high-risk samples rather than general population samples (Verdoux \& Cougnard, 2003) and reviewers have stated that the application of these strategies at a population level would not be supported at this stage (Drake \& Lewis, 2005; Yung, 2003). The second criticism is that there is a high false-positive rate in all of these studies, with the majority of participants not developing psychotic disorder. Thus many people identified as being at risk of psychotic disorder may not actually be so. Critics argue that these false positive cases are then subjected to unnecessary and potentially harmful treatment (Warner, 2005). What is often overlooked by such critics is that many of the people presenting to these clinics are not free of distress or reduced functioning, and while many may not be prodromal for psychosis, they are likely to be either experiencing or developing other disorders. It has been noted that the point at which the prodrome of moderate to severe depression and that of psychosis are differentiable is on the emergence of frank psychotic symptoms (Hafner \& Maurer, 2006). Proponents of early intervention argue also for the application in psychiatry of the clinical staging model which is well-known in other areas of medicine (McGorry et al., 2006; Yung et $a l$, in press). In this model earlier identification would be associated with less invasive treatments (e.g. psychoeducation rather than medication). As in other illnesses, progression of disorder would indicate increasing levels of treatment. It also allows for other disorders apart from psychotic disorders to be treated in a timely manner if they arise.

One of the interesting findings from pre-onset clinics is that over their period of existence the transition rate they are observing is decreasing (Yung et al., 2006, in press). A reason which may explain this is that as they are becoming better known in their service areas, these clinics are being referred clients at a much earlier stage of psychopathology (Yung et al., 2006). Therefore, these people, if they are to transition, are less likely than previous cohorts to do so within the period of time covered by the study (usually 6-12 months). Evidence that this may be the case is that the study with the largest transition rate (70\%) also has the longest follow-up period ( 9.4 years) (Klosterkotter et al., 2001).

\section{Pre-onset phase interventions: Can we stop transition to psychosis?}

There are a number of aims to intervention in the preonset phase. They are: to prevent transition to psychosis; to treat current problems, such as comorbid depressive or anxiety symptoms or syndromes and; to ensure that should transition occur the individual is already well engaged with treatment, minimising duration of untreated psychosis (DUP) and facilitating non-traumatic entry into an early intervention program (Yung et al., 2004). There have been three main forms of intervention in preonset clinics. These are: psychotherapy targeted specifically at positive symptoms, usually cognitive-behavioural in orientation (Morrison et al., 2004; Yung et al., 2004), other syndrome targeted psychotherapy (e.g. for depressive symptoms) and pharmacotherapy (i.e. for mood or anxiety disorders which frequently are present in people presenting to pre-onset clinics (Rosen et al., 2006; Svirskis et al., 2005; Yung et al., 2004), and finally low dose anti-psychotic medication. 
Four studies have examined the effectiveness of various strategies in reducing transition to psychosis (McGlashan et al., 2006; McGorry et al., 2002; Morrison et al., 2004; Nordentoft et al., 2006). Three found a significant difference in the transition to psychosis between intervention and control groups (McGorry et al., 2002; Morrison et al., 2004; Nordentoft et al., 2006), whereas the fourth (McGlashan et al., 2006) found a non-significant difference but with a trend in the direction of medication being effective. Two of the three studies which found a difference used a combination of psychosocial and pharmacological intervention (McGorry et al., 2002; Nordentoft et al., 2006) whereas Morrison et al. used CBT alone (Morrison et al., 2004). In contrast McGlashan et al. was the only study to use a pharmacological intervention alone. This may indicate a number of things. The first is the possibility that the McGlashan study was underpowered and that drawing inferences from this alone would be premature. Alternatively, it may be that in this phase psychological and psychosocial interventions either alone or in combination with pharmacotherapy may be more powerful than pharmacological interventions alone. Further research is required to resolve which elements of an intervention are essential at this time point and for how long they need to be applied. Development of this knowledge would be a useful contribution towards the elucidation of a working clinical staging model as proposed by McGorry et al. (2006).

Critics have pointed out that some of the risks associated with treatment in this phase are the mislabelling, potential stigmatisation and exposure to unnecessary treatments (Morrison et al., 2004; Warner, 2005) of falsepositives, particularly where treatment is with antipsychotic medication. There are two approaches to this issue. The first is the route taken by Morrison's group and use only a psychological intervention, which they argue is less likely to lead to deleterious side-effects than a pharmaceutical intervention (Morrison et al., 2004). The second route is that advocated by treatment guidelines which is the cautious use of medication (McGorry et al., 2005). It is true that the largest risk in pre-onset treatment is the unnecessary administration of neuroleptic medication. Very early identification, allowing less invasive treatment is likely to reduce the need for pharmacological interventions. While many people attending pre-onset clinics are not experiencing a current psychotic episode, this does not necessarily mean that they are not experiencing any mental illness. Often they may be experiencing either sub-threshold or diagnosable symptoms of affective or anxiety problems (Rosen et al., 2006; Ruhrmann et al., 2005; Svirskis et al., 2005; Yung et al.,
2004). Whether these syndromes are precursors to a psychotic episode or not, they warrant treatment.

In the last ten years since the establishment of the first pre-onset clinic great advances have been made in developing criteria to identify those at risk of developing psychosis. Treatment for this identified group has been developed which in a majority of studies shows an ability to significantly reduce the rate of transition to psychosis and reduce symptomatology. While this is promising, critics of both the identification and intervention process raise some valid concerns. In order to address these concerns two key developments are required. Firstly the continued improvement of the accuracy of predictive tools reducing the false positive rate as much as possible. Secondly, developing a knowledge of which interventions are required at what stage so as to reduce the exposure of people to unnecessary iatrogenic damage.

\section{POST ONSET}

\section{Duration of untreated psychosis - is it related to outcome?}

One of the debates that occurred was whether or not there was a relationship between the DUP and the outcome of illness. Those advocating that there was a relationship were countered by those who argued that prolonged DUP and poor outcome were both caused by a third variable that independently led to prolonged avoidance of care (McGlashan, 1999; McGorry, 2000; Verdoux et al., 2001; Warner, 2005).

Many studies have examined whether or not DUP was related to outcome in first episode groups (Edwards et al., 2002; Harrigan et al., 2003; Harris et al., 2005; Ho et al., 2000; McGorry, 2000). There have been criticisms of studies with findings that supported and studies with findings that did not support DUP being associated with poorer outcome (McGorry \& Killackey. 2002; Warner, 2005). Until recently the question has not been able to be resolved (Drake \& Lewis, 2005; Verdoux \& Cougnard, 2003). However, two meta-analyses of this question have now been conducted (Marshall et al., 2005; Perkins et al., 2005). Both studies found that there was a consistent small to moderate effect of DUP on a range of outcome variables including symptomatic and functional recovery. Both meta-analyses found that the effect of DUP on outcome was independent of potential confounders, and that prolonged DUP had a negative impact on recovery. It would therefore seem that the weight of evidence agrees with the proponents of the early intervention model that DUP is related to poor outcome. 


\section{Can duration of untreated psychosis be reduced?}

The obvious question that arises if prolonged DUP is related to poorer outcome is whether DUP can be reduced. The Norwegian TIPS study (Johannessen et al., 2005 ) is the best study thus far to examine whether a specialised programme can act to reduce DUP (Drake \& Lewis, 2005). Comparing two regions with an early psychosis detection programme to two areas without, it was found that DUP can be reduced with medians being 5 weeks and 16 weeks respectively (Melle et al., 2004). There were differences in favour of the early detection group at baseline on a number of variables measured by the PANSS and the GAF (Melle et al., 2004), and also reduced suicidality (Melle et al., 2006). However, there was no difference between quality of life or social functioning (Melle et al., 2005), deterioration in which, the authors suggest, may precede symptom onset. While it would be valuable if the TIPS study were replicated, the evidence from this one study suggests that a combination of service provision and public education can act to reduce the duration of untreated psychosis.

\section{After 15 years is there evidence early intervention in psychosis works?}

There are two trials which have used a randomised design to assess the effectiveness of outcomes of first episode services. The OPUS trial in Denmark randomly assigned 547 patients to either an integrated treatment in which they were provided with two years of service or to standard treatment (Thorup et al., 2005). The integrated treatment was more intense and assertive and covered a wider range of domains including family therapy, and social skills training. A low caseload ratio of 1:10 was maintained. The control condition was treatment at a standard service in Copenhagen or Aarhus in which caseloads were higher (1:25). The results from the study indicated that the integrated treatment had beneficial effects on symptomatic and functional outcome at one and two years (Petersen et al., 2005; Thorup et al., 2005) as well as a perceived reduction in family burden (Jeppesen $e t$ al., 2005). The more assertive nature of the early intervention model is seen in the fact that patients in the integrated treatment had an average of 77 contacts over the two years compared to 27 in the standard treatment group (Thorup et al., 2005).

The second trial is the Lambeth Early Onset (LEO) trial (Craig et al., 2004). The LEO trial randomised those presenting for a first episode psychosis (or a second episode where there had been failure to engage previous- ly) to either receive treatment from standard services or from a new early intervention service. It was found that there was a beneficial effect of the early intervention on readmissions, relapses and drop-outs. However, when adjustments were made the relapse rate became non-significant (Craig et al., 2004). Further analysis of this study showed that the intervention group were more compliant with medication, spent more time engaged in educational or vocational pursuits, and established or re-established relationships better than the control group (Garety et al., 2006). The LEO trial shows that early intervention can achieve gains in both clinical and functional aspects of early psychosis.

\section{Is early intervention too expensive?}

One question that may be asked is whether or not the more intense nature of the early intervention service is so expensive as to not be viable. An answer to this question is found in the three year results of the Parachute project (Cullberg et al., 2006) which compared an early intervention model of service with both an historical control and a high quality prospective control. Although there were no differences in patient cost between the programs in the second and third years of the project, in the first year the total costs of the early intervention condition were significantly lower than the prospective control condition ( $\$ 11,614$ vs $\$ 23,192 \mathrm{p}<0.05$ ) (Cullberg et al., 2006). This was mainly due to lower inpatient costs as the early intervention model is more focused on treatment in the community. This replicates earlier similar findings (Mihalopoulos et al., 1999).

\section{What is the 'early' period?}

Another important question is for what period should 'early' intervention continue? Birchwood identified the first five years as being a critical period (Birchwood \& Fiorillo, 2000), and yet many early intervention programs provide only 18 months or at best 3 years. While many outcome studies look at one year outcomes (Addington $e t$ $a l ., 2003 \mathrm{a}, \mathrm{b}$ ), the high rate of relapse in young people with psychosis (Gleeson et al., 2005) has led some to suggest that a longer continuity of care within first episode programmes is warranted, and that there may even be ethical issues about referral to mainstream agencies during this critical period (Linszen et al., 2001) as is seen with data about suicide rates (Power et al., 2003) and levels of substance use (Wade et al., 2006). Clearly the length of treatment required in optimal early psychosis services warrants further investigation. 


\section{NEW DIRECTIONS AND CHALLENGES}

Staging of interventions for a phase specific illness:

Within early intervention, psychosis has been conceptualised as an illness consisting of phases, each to be considered and treated differently (McGorry et al., 2005). In physical illnesses the idea of progression through different phases is not remarkable. However until recently a similar model had not been articulated for mental illness. McGorry et al. (2006) have now suggested a staged model of mental illness. The full development of this model will allow for the earliest identification of mental illness. Further, earlier identification will allow for less invasive treatments such as psychosocial interventions to be utilised at an earlier phase. The implementation of this model will once again challenge the orthodox positions of many who believe that treatment for mental illness must wait until full blown illness occurs, or who do not see the need for a youth specific model of mental illness (Birleson et al., 2001). Particularly so as implementation requires a focus on youth mental health, extending adolescent services up to age 25 to cover the age span with the highest prevalence and incidence for mental disorders (McGorry, in press). It will require adjustments in criteria for access to services to include those with as yet undifferentiated, non-specific symptomatology. As this approach develops there will be issues that will need to be resolved. These include: how long must a less benign treatment be applied before it can be withdrawn with minimal risk of relapse; what are the markers of each stage of illness; at what stage are which treatments required and; how can those in the earliest stages be identified.

\section{To aim for a recovery beyond symptom management}

Neo-Kraeplinian concepts of inevitable decline in psychotic illness have long been anathema to those in early intervention research and practice (McGorry \& Killackey, 2002). Despite this much of the work in the last 15 years has concentrated only on improved symptomatic outcome. As early intervention continues to develop, concepts of recovery must expand beyond symptoms to include functional recovery. This must include returning to work or education (Killackey et al., 2006) as these are the means by which other areas of functioning such as social participation are most likely to occur. It is of interest that vocational rehabilitation has some of the strongest efficacy evidence (Crowther et al., 2001) and yet is so rarely implemented in routine practice beyond referral to external employment agencies whose ability to help those with mental illness is typically abysmal (Marwaha \& Johnson, 2004).

\section{To finally close the gap between what can be done and what is done}

As mentioned there is strong research evidence that vocational recovery is a highly effective intervention. Likewise other interventions such as McFarlane family therapy and cognitive behaviour therapy for psychosis also have good research evidence supporting their use in early psychosis treatment (McGorry et al., 2005). And yet, these evidence based techniques are not often part of routine clinical care. The inclusion of good psychosocial interventions alongside evidence based pharmacotherapy needs to be promoted if the best services are to be provided to young people with first episode psychosis (McGorry, 2005).

In order to meet the challenges of these new directions there is still a great need for further reform. Part of this reform, as always, is in the way services are structured and function. Part of it too must be in greater awareness of mental health in the community. This will require education. It will also require people to be aware of what to do in the case of identifying early signs of mental illness in themselves or in someone they know. Mental health First Aid (Kitchener \& Jorm, 2002) is an ideal method for achieving these aims. Another key reform will be extending the period of time in which someone will be able to be treated. As identification becomes more accurate and earlier, treatment has the potential to happen over a longer period. This must be allowed for. This early detection and ongoing treatment is not only likely to reduce the severity of illness and disability associated with it, but also to have effect on other key domains such as suicide and substance use.

\section{CONCLUSION}

While there have been many developments in early psychosis over the last 15 years, there are still many more that need to occur. There is a large gap between what we know can work and what actually gets done. There are still too many people whose first experience of psychiatric care occurs in a traumatic and coercive way. Often, mental health systems require 'proof of illness' before providing treatment, rather than being willing to engage with a young person with an as yet undifferentiated set of symptoms. Despite having moved away from the old fashioned institutional management of chronic illness, 
current approaches can not be described as recovery oriented in focus. Much of the therapeutic nihilism so often written of in the early years of the early intervention movement still exists in mental health systems. This is particularly seen in the lack of focus on functional recovery in most mainstream mental health services. And despite having moved from long-term care, young people now often lack the ongoing care they require as they move through the critical period of illness. This is seen in relapse and suicide rates, the amount of substance use and the poor level of functioning in several life domains of many people with psychotic illnesses.

The early intervention concepts developed in early psychosis research and practice are beginning to expand to other areas of mental health. This expansion must be accompanied by a renewed focus on developing, researching and implementing interventions which aim at the broadest possible definition of recovery. In this way it is hoped that the right to a healthy, full and productive life will be equally available to those who experience a mental illness as it is to those who don't.

Early intervention in psychosis began as not only a new clinical paradigm and the focus of a nascent research field, but also as a movement of reform advocating for better mental health services for young people. Into the future it is imperative that the reformist element is not lost as early intervention becomes a mainstream approach to mental illness.

\section{REFERENCES}

Addington J., Leriger E. \& Addington D. (2003a). Symptom outcome 1 year after admission to an early psychosis program. Canadian Journal of Psychiatry 48, 204-207.

Addington J., Young J. \& Addington D. (2003b). Social outcome in early psychosis. Psychological Medicine 33, 1119-1124.

Bell R.Q. (1992). Multiple risk cohorts and segmenting risk as solutions to the problems of false positives in risk for the major psychoses. Psychiatry 55, 370-381.

Birchwood M. \& Fiorillo A. (2000). The critical period for early intervention. Psychiatric Rehabilitation Skills, Special Issue 4, 182-198.

Birleson P. Luk E.S. \& Mileshkin C (2001). Better mental health services for young people: responsibility, partnerships and projects. Australian and New Zealand Journal of Psychiatry 35, 36-44.

Craig T.K., Garety P., Power P., Rahaman N., Colbert S., FornellsAmbrojo M. \& Dunn G. (2004). The Lambeth Early Onset (LEO) Team: randomised controlled trial of the effectiveness of specialised care for early psychosis. British Medical Journal 329, 1067

Crowther R.E., Marshall M., Bond G.R. \& Huxley P. (2001). Helping people with severe mental illness to obtain work: Systematic review. British Medical Journal 322, 204-208.

Cullberg J., Mattsson M., Levander S., Holmqvist R., Tomsmark L., Elingfors C. \& Wieselgren I.M. (2006). Treatment costs and clinical outcome for first episode schizophrenia patients: a 3-year follow-up of the Swedish 'Parachute Project' and Two Comparison Groups. Acta Psychiatrica Scandinavica 114, 274-281.
Drake R.J. \& Lewis S.W. (2005). Early detection of schizophrenia. Current Opinion in Psychiatry 18, 147-150.

Edwards J., Harrigan S.M., McGorry P.D. \& Amminger P.G. (2002) Duration of untreated psychosis (DUP) and outcome in schizophrenia. Psychological Medicine 32, 563-564.

Francey S.M., Jackson H.J., Phillips L.J., Wood S.J., Yung A.R. \& McGorry P.D. (2005). Sustained attention in young people at high risk of psychosis does not predict transition to psychosis. Schizophrenia Research 79, 127-136.

Garety P.A., Craig T.K., Dunn G., Fornells-Ambrojo M., Colbert S., Rahaman N., Read J. \& Power P. (2006). Specialised care for early psychosis: symptoms, social functioning and patient satisfaction: randomised controlled trial. British Journal of Psychiatry 188, 37. 45.

Gleeson J.F., Rawlings D., Jackson H.J. \& McGorry P.D. (2005). Early warning signs of relapse following a first episode of psychosis. Schizophrenia Research 80, 107-111.

Hafner H. \& Maurer K. (2006). Early detection of schizophrenia: current evidence and future perspectives. World Psychiatry 5, 130-138.

Hambrecht M., Lammertink M., Klosterkötter J., Matuschek E. \& Pukrop R. (2002). Subjective and objective neuropsychological abnormalities in a psychosis prodrome clinic. British Journal of Psychiatry 181, s30-s37.

Harrigan S.M., McGorry P.D. \& Krstev H. (2003). Does treatment delay in first-episode psychosis really matter? Psychological Medicine $33,97-110$.

Harris M.G., Henry L.P., Harrigan S.M., Purcell R., Schwartz O.S., Farrelly S.E., Prosser A.L., Jackson H.J. \& McGorry P.D. (2005). The relationship between duration of untreated psychosis and outcome: an eight-year prospective study. Schizophrenia Research 79, 85-93.

Ho B.C., Andreasen N.C., Flaum M., Nopoulos P. \& Miller D. (2000). Untreated initial psychosis: its relation to quality of life and symptom remission in first-episode schizophrenia. American Journal of Psychiatry 157, 808-815.

Jeppesen P., Petersen L., Thorup A., Abel M.B., Oehlenschlaeger J., Christensen T.O., Krarup G., Hemmingsen R., Jorgensen P. \& Nordentoft M. (2005). Integrated treatment of first-episode psychosis: effect of treatment on family burden: OPUS trial. British Journal of Psychiatry, Supplement 48, s85-90.

Johannessen J.O., Larsen T.K., Joa I., Melle I., Friis S., Opjordsmoen S., Rund B.R., Simonsen E., Vaglum P. \& McGlashan T.H.. (2005). Pathways to care for first-episode psychosis in an early detection healthcare sector: part of the Scandinavian TIPS study. British Journal of Psychiatry, Supplement 48, s24-s28.

Killackey E. \& Yung A.R. (2007). Effectiveness of early intervention in psychosis. Current Opinion in Psychiatry 20, 121-125.

Killackey E.J., Jackson H.J., Gleeson J., Hickie I.B. \& McGorry P.D. (2006). Exciting Career Opportunity Beckons! Early Intervention and Vocational Rehabilitation in First Episode Psychosis: Employing Cautious Optimism. Australian and New Zealand Journal of Psychiatry 40, 951-962.

Kitchener B.A. \& Jorm A.F. (2002). Mental health first aid training for the public: evaluation of effects on knowledge, attitudes and helping behavior. BMC Psychiatry 2, 10.

Klosterkotter J., Hellmich M., Steinmeyer E.M. \& Schultze-Lutter F. (2001). Diagnosing schizophrenia in the initial prodromal phase. Archives of General Psychiatry 58, 158-164.

Linszen D., Dingemans P. \& Lenior M.E. (2001). Early intervention and a five year follow up in young adults with a short duration of untreated psychosis: Ethical implications. Schizophrenia Research 51, 55-61.

Marshall M., Lewis S., Lockwood A., Drake R., Jones P. \& Croudace T. (2005). Association between duration of untreated psychosis and outcome in cohorts of first-episode patients: a systematic review. Archives of General Psychiatry 62, 975-983.

Marwaha S. \& Johnson S. (2004). Schizophrenia and employment: A review. Social Psychiatry and Psychiatric Epidemiology 39, 337-349. 
Mason O., Startup M., Halpin S., Schall U., Conrad A. \& Carr V. (2004). Risk factors for transition to first episode psychosis among individuals with 'at-risk mental states'. Schizophrenia Research 71, 227 237.

McGlashan T.H. (1999). Duration of untreated psychosis in first-episode schizophrenia: marker or determinant of course? Biological Psychiatry 46, 899-907.

McGlashan T.H., Zipursky R.B., Perkins D., Addington J., Miller T., Woods S.W., Hawkins K.A., Hoffman R.E., Preda A., Epstein I., Addington D., Lindborg S., Trzaskoma Q., Tohen M. \& Breier A (2006). Randomized, double-blind trial of olanzapine versus placebo in patients prodromally symptomatic for psychosis. American Journal of Psychiatry 163, 790-799.

McGorry P.D. (2000). Evaluating the importance of reducing the duration of untreated psychosis. Australian and New Zealand Journal of Psychiatry 34, Suppl. 34, s145-s149.

McGorry P. (2005). 'Every me and every you': responding to the hidden challenge of mental illness in Australia. Australasian Psychiatry 13 , 3-15.

McGorry P.D. (in press). Investing in youth mental health is a best buy Medical Journal of Australia.

McGorry P.D. \& Killackey E.J. (2002). Early intervention in psychosis: a new evidence based paradigm. Epidemiologia e Psichiatria Sociale $11,237-247$.

McGorry P.D., Yung A.R., Phillips L.J., Yuen H.P., Francey S., Cosgrave E.M., Germano D., Bravin J., McDonald T., Blair A., Adlard S. \& Jackson H. (2002). Randomized controlled trial of interventions designed to reduce the risk of progression to first-episode psychosis in a clinical sample with subthreshold symptoms. Archives of General Psychiatry 59, 921-928.

McGorry P., Killackey E., Lambert T. \& Lambert M. (2005). Royal Australian and New Zealand College of Psychiatrists clinical practice guidelines for the treatment of schizophrenia and related disorders. Australian and New Zealand Journal of Psychiatry 39, 1-30.

McGorry P.D., Hickie I.B., Yung A.R., Pantelis C. \& Jackson H.J. (2006). Clinical staging of psychiatric disorders: a heuristic framework for choosing earlier, safer and more effective interventions. Australian and New Zealand Journal of Psychiatry 40, 616-622.

Melle I., Haahr U., Friis S., Hustoft K., Johannessen J.O., Opjordsmoen S., Simonsen E., Rund B.R., Vaglum P. \& McGlashan T. (2005). Reducing the duration of untreated first-episode psychosis - effects on baseline social functioning and quality of life. Acta Psychiatrica Scandinavica $112,469-473$

Melle I., Larsen T.K., Haahr U., Friis S., Johannessen J.O., Larsen T.K., Opjordsmoen S., Rund B.R., Simonsen E., Vaglum P. \& McGlashan T. (2004). Reducing the duration of untreated first-episode psychosis: effects on clinical presentation. Archives of General Psychiatry 61, 143-150.

Melle I., Johannesen J.O., Svein Friis S., Haahr U., Joa I., Larsen T.K. Opjordsmoen S., Rund B.R., Simonsen E., Vaglum P. \& McGlashan T. (2006). Early detection of the first episode of schizophrenia and suicidal behavior. American Journal of Psychiatry 163, 800-804.

Mihalopoulos C., McGorry P.D. \& Carter R.C. (1999). Is phase-specific, community-oriented treatment of early psychosis an economically viable method of improving outcome? Acta Psychiatrica Scandinavica 100, 47-55.

Morrison A.P., French P., Walford L., Lewis S.W., Kilcommons A., Green J., Parker S. \& Bentall R.P. (2004). Cognitive therapy for the prevention of psychosis in people at ultra-high risk: randomised controlled trial. British Journal of Psychiatry 185, 291-297.

Mrazek P. \& Haggerty R. (1994). Reducing Risks for Mental Disorders: Frontiers for Preventitive Intervention Research. National Academy Press: Washington DC.

NICE (2003). Schizophrenia: Full National Clinical Guideline on Core Interventions in Primary and Secondary Care. Gaskell \& The British Psychological Society: London.
Nordentoft M., Thorup A., Petersen L., Ohlenschlaeger J., Melau M., Christensen T.O., Krarup G., Jorgensen P. \& Jeppesen P. (2006) Transition rates from schizotypal disorder to psychotic disorder for first-contact patients included in the OPUS trial. A randomized clinical trial of integrated treatment and standard treatment. Schizophrenia Research 83, 29-40.

Perkins D.O., Gu H., Boteva K. \& Lieberman J.A. (2005). Relationship between duration of untreated psychosis and outcome in first-episode schizophrenia: a critical review and meta-analysis. American Journal of Psychiatry 162, 1785-1804.

Petersen L., Nordentoft M., Jeppesen P., Ohlenschaeger J., Thorup A., Christensen T.O., Krarup G., Dahlstrom J., Haastrup B. \& Jorgensen P. (2005). Improving 1-year outcome in first-episode psychosis: OPUS trial. British Journal of Psychiatry, Supplement 48, s98-103.

Power P.J., Bell R.J., Mills R., Herrman-Doig T., Davern M., Henry L., Yuen H.P., Khademy-Deljo A. \& McGorry P.D. (2003). Suicide prevention in first episode psychosis: the development of a randomised controlled trial of cognitive therapy for acutely suicidal patients with early psychosis. Australian and New Zealand Journal of Psychiatry $37,414-420$.

Rosen J.L., Miller T.J., D'Andrea J.T., McGlashan T.H. \& Woods S.W. (2006). Comorbid diagnoses in patients meeting criteria for the schizophrenia prodrome. Schizophrenia Research 85, 124-131

Ruhrmann S., Schultze-Lutter F., Maier W. \& Klosterkotter J. (2005). Pharmacological intervention in the initial prodromal phase of psychosis. European Psychiatry 20, 1-6.

Sullivan H. (1927). The onset of schizophrenia. American Journal of Psychiatry 6, 105-134

Svirskis T., Korkeila J., Heinimaa M., Huttunen J., Ilonen T., Ristkari T., McGlashan T. \& Salokangas R.K. (2005). Axis-I disorders and vulnerability to psychosis. Schizophrenia Research 75, 439-446.

Thorup A., Petersen L., Jeppesen P., Ohlenschlaeger J., Christensen T., Krarup G., Jorgensen P. \& Nordentoft M. (2005). Integrated treatment ameliorates negative symptoms in first episode psychosis-results from the Danish OPUS trial. Schizophrenia Research 79, 95 105.

Verdoux H. \& Cougnard A. (2003). The early detection and treatment controversy in schizophrenia research. Current Opinion in Psychiatry 16, 175-179.

Verdoux H., Liraud F., Bergey C., Assens F., Abalan F. \& van Os J. (2001). Is the association between duration of untreated psychosis and outcome confounded? A two year follow-up study of first-admitted patients. Schizophrenia Research 49, 231-241.

Wade D., Harrigan S., Edwards J., Burgess P.M., Whelan G. \& McGorry P.D. (2006). Substance misuse in first-episode psychosis: 15-month prospective follow-up study. British Journal of Psychiatry 189, 229234.

Warner R. (2001). The prevention of schizophrenia: what interventions are safe and effective? Schizophrenia Bulletin 27, 551-562.

Warner R. (2002). Limitations of the Bonn Scale for the Assessment of Basic Symptoms as a screening measure. Archives of General Psychiatry 59, 470-471.

Warner R. (2005). Problems with early and very early intervention in psychosis. British Journal of Psychiatry, Supplement 48, s104-s107.

Yung A.R. (2003). Commentary: The Schizophrenia Prodrome: A HighRisk Concept. Schizophrenia Bulletin 29, 859-865.

Yung A.R., Phillips L.J. \& McGorry P.D. (2004). Treating Schizophrenia in the Prodromal Stage. Taylor \& Francis: London.

Yung A.R., Stanford C., Cosgrave E., Killackey E., Phillips L., Nelson B. \& McGorry P.D. (2006). Testing the Ultra High Risk (prodromal) criteria for the prediction of psychosis in a clinical sample of young people. Schizophrenia Research 84, 57-66.

Yung A.R., Yuen H.P., Berger G., Francey S., Hung T., Nelson B., Phillips L. \& McGorry P.(in press).Declining transition rate in Ultra High Risk (prodromal) services: dilution or reduction of risk? Schizophrenia Bulletin. 